\title{
Experimental and Fluid-dynamic Analysis of a Micro Wind Turbine in Urban Area
}

\author{
Marco Milanese ${ }^{1, *}$, Arturo de Risi ${ }^{1}$, Domenico Laforgia ${ }^{1}$ \\ ${ }^{1}$ Department of Engineering for Innovation - University of Salento, Lecce, Italy \\ * Corresponding author. Tel: +39 0832297760, Fax: +39 0832297777, E-mail: marco.milanese@unisalento.it
}

\begin{abstract}
In urban areas, the evaluation of the energy outcome of a horizontal axis micro wind turbine depends on several factors such as mean wind velocity, location, turbulence, etc. To maximize the micro wind turbine efficiency it is important to define the best location. The present paper focuses on the definition of common rules for micro siting in urban areas.

In this work, the efficiency of a $1 \mathrm{kWp}$ horizontal-axis wind turbine has been evaluated, by means of CFD and experimental data. The numerical results have been compared with the experimental data collected over a period of time of three years, by using a measurement equipment installed on the roof of the Engineering building at the University of Salento. The results have shown that horizontal axis wind turbines suffer from wake effect due to buildings, therefore best sites in urban area have to be identified by a careful fluid dynamic analysis aimed at evaluating all causes that can reduce significantly the performance of the generator.
\end{abstract}

Keywords: Micro wind turbine, best location, experimental and fluid-dynamic analysis

\section{Introduction}

In the last years, prices of oil have achieved strong variations on international markets. These occurrences have underlined the very important role of energy as fundamental factor for human activity $[1,2,3]$. In this scenario, small/micro wind generators are gaining an important role due to both the low environmental impact and the possibility to avoid big electrical networks.

Several authors have studied the topic of microgeneration, by taking into account both technical and social aspects $[4,5,6]$. Kelleher e Ringwood [7] developed software to estimate the economic performance of small/micro solar and wind plants. Watson [8] carried out studies about the microgeneration management techniques considering power supply issues. Besides, in order to estimate micro wind turbine performance several studies have been carried out by using computational fluid dynamic models (CFD), since they can show an exhaustive draft about the wind flow around the micro turbine in any meteorological conditions, allowing saving time and costs $[9,10]$.

For evaluating the economic convenience about the installation of a micro wind turbine in urban area, it is important to calculate positive and negative effects of buildings or other obstacles on the aerogenerator performance. For this reason, the present work focuses on the best siting of small horizontal-axis wind turbines in urban area. Particularly, an aerogenerator has been installed on the roof of the Engineering building at the University of Salento and monitored over a period of time of three years.

During experimental testes it was observed a perpetual transient condition of the microturbine that reduces its performance. Then CFD simulations have been carried out to fully understand the relationship between the aerogenerator performance measured under several meteorological conditions and the shape of the building where the plant is installed. In this way, a useful rule for best placing of horizontal-axis wind turbines in urban areas has been obtained. 


\section{Experimental setup and numerical model}

\subsection{Description of the experimental setup}

In this work, an experimental apparatus has been developed for monitoring the performance of a horizontal axis micro wind turbine $(1 \mathrm{kWp})$.

Anemometer, PLC, analogic/digital conversion unit, web server, voltage transducers and current transducers composed the measurement apparatus. Table 1 reports the main technical specifications of the experimental setup.

Table 1. Mean technical features of the plant

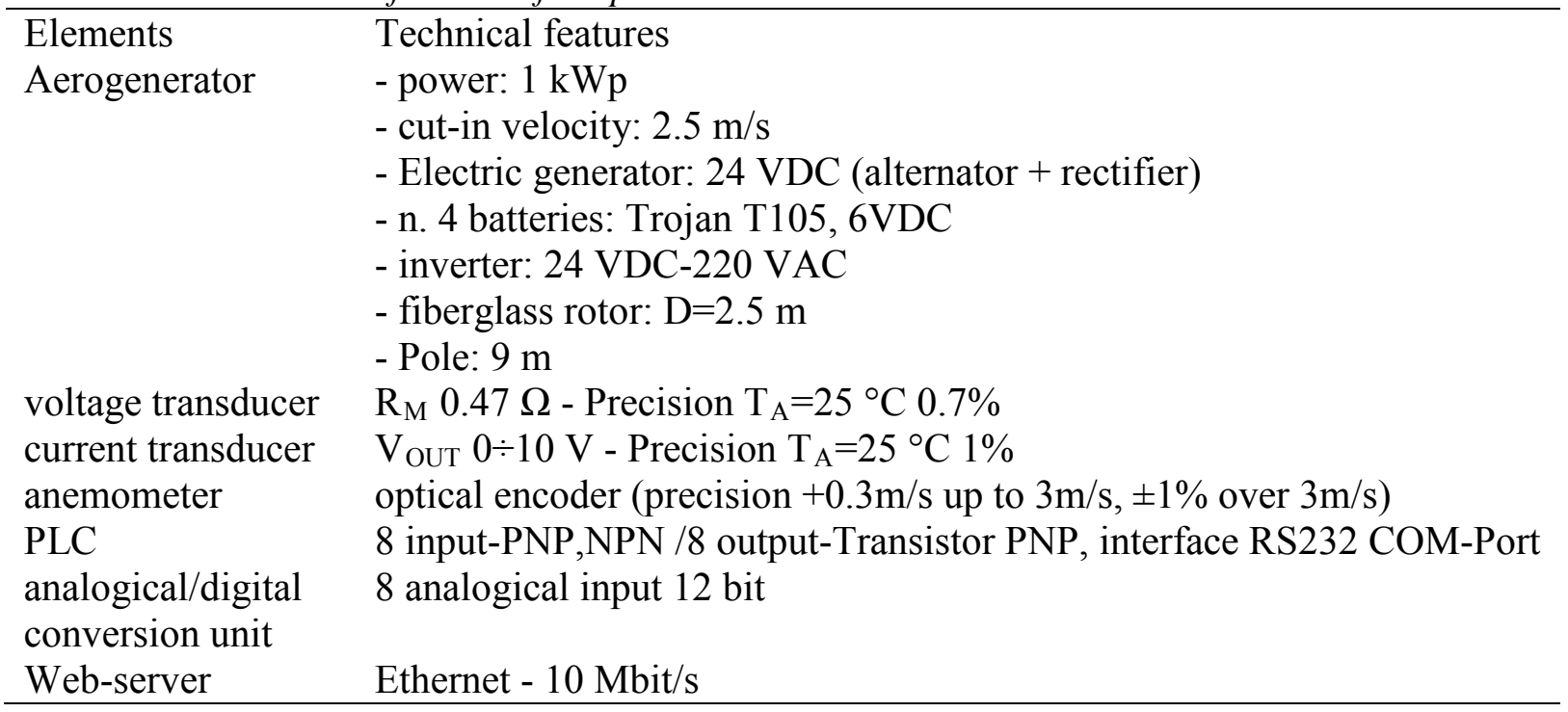

The whole system was controlled by a PLC that acquires and processes several signals and monitors all parameters under investigation. Besides the measures were viewable in real time on an Internet web site and stored on a remote hard disk.

\subsection{CFD Model}

In order to study the wind microturbine performance, a 3D model of the building has been drawn, as Fig. 1 shows. The total height from the ground of the aerogenerator is equal to 20 m.

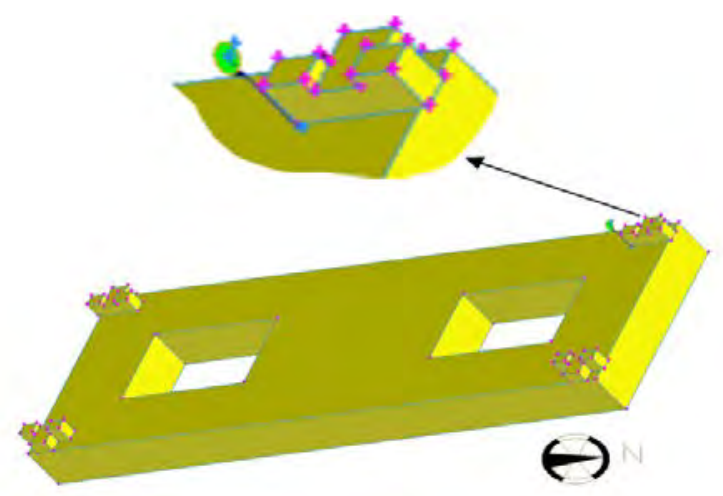

Fig. 1. 3D model of the building where the aerogenerator has been installed.

The fluid dynamic simulation domain has been obtained by subtracting the building volume to a parallelepiped sufficiently large to consider undisturbed fluid-dynamic conditions on the boundary. 
For meshing the volume, tetrahedral elements whose size was in the range between 0.2 and 2 $\mathrm{m}$ have been used. The computational cell size has been selected to reduce the maximum computational error and to obtain grid-independent solutions.

The mesh sensitivity analysis has been performed by comparing the results from several simulations carried out with different mesh resolutions.

Table 2. Sensitivity analysis results

\begin{tabular}{ccc}
\hline Cells $(\mathrm{n})$ & Mean wind velocity close to the aerogenerator $(\mathrm{m} / \mathrm{s})$ & Variation $(\%)$ \\
\hline 579'596 & 7.93 & - \\
1'084'494 & 8.16 & $2.8 \%$ \\
2'552'154 & 8.26 & $4.1 \%$ \\
\hline
\end{tabular}

As Table 2 shows, by incrementing the number of cells from 579'596 to 2'552'154 the mean wind velocity close to the aerogenerator changes within $4.1 \%$ and this difference outcomes equal to $1.3 \%$ switching the number of cells from 1'084'494 to 2'552'154. So it is reasonable to use the denser grid, since further incrementing the number of cells, advantages shouldn't be enough to justify the relative increment of calculation time.

Numerical simulations have been carried out by using FLUENT software and studying eight wind directions with an angular difference equal to $45^{\circ}$ and wind velocity within the range $4 \div 8 \mathrm{~m} / \mathrm{s}$. This range has been fixed by taking into account the following considerations:

- Up to $4 \mathrm{~m} / \mathrm{s}$, the electric power is lower than $5 \%$ of the nominal power and the data statistical dispersion is much large with respect to the measured values: this issue does not allow to do a comparison between experimental and numerical data;

- Over $8 \mathrm{~m} / \mathrm{s}$, there are not enough data (less than $2 \%$ ).

Turbulence has been evaluated using the standard k- $\varepsilon$ turbulence model.

\section{Discussion of results}

\subsection{Measured data analysis}

The aerogenerator was installed on the roof of the Engineering building at the University of Salento. The following coordinates individuate the exact location: $40^{\circ} 20^{\prime} 03$ " N, $018^{\circ} 06^{\prime} 51^{\prime \prime}$ $\mathrm{E}$ and $35 \mathrm{~m}$ with respect to the mean sea level.

The wind microturbine has been monitored over a period of three years $(2005,2006$ a nd 2007), measuring several parameters: wind velocity and direction, electric current, voltage and generated power. All parameters have been registered each 10 minutes.

For modeling wind data the Weibull function has been used in accord with following equation.

$$
P\left(v<v_{i}<v+d v\right)=P(v>0) \frac{k}{c}\left(\frac{v_{i}}{c}\right)^{k-1} \exp \left(-\left(\frac{v_{i}}{c}\right)^{k}\right) d v
$$

Where $c$ is the scale parameter, $k$ is the shape factor, $v_{i}$ is a generic wind velocity value, $d v$ is the wind velocity increment, $P\left(v<v_{i}<v+d v\right)$ is the probability to register a wind velocity within the range $v$ e $v+d v$ and $P(v>0)$ is the probability to register a wind velocity major to zero.

Weibull function is completely defined if $c$ and $k$ are known: these coefficients have been calculated by using the modified maximum probability method and considering a wind velocity step equal to $0.1 \mathrm{~m} / \mathrm{s}$. Table 3 reports the values of $c$ and $k$ for the period under 
investigation $(2005 \div 2007)$, whereas Fig. 2 shows the comparison between experimental data and the Weibull curve.

Table 3. Weibull function parameters for the period under investigation $(2005 \div 2007)$

\begin{tabular}{rcccrr}
\multicolumn{1}{c}{ Year } & $k$ & $\begin{array}{c}c \\
(\mathrm{~m} / \mathrm{s})\end{array}$ & $\begin{array}{c}\text { Most probable velocity } \\
(\mathrm{m} / \mathrm{s})\end{array}$ & $\begin{array}{c}\text { Mean velocity } \\
(\mathrm{m} / \mathrm{s})\end{array}$ & $\begin{array}{c}\text { Standard deviation } \\
(\mathrm{m} / \mathrm{s})\end{array}$ \\
\hline 2005 & 1.658 & 3.457 & 1.98 & 3.09 & 1.91 \\
2006 & 1.649 & 3.420 & 1.94 & 3.06 & 1.90 \\
2007 & 1.669 & 3.444 & 1.99 & 3.08 & 1.89 \\
Mean values & 1.659 & 3.440 & 1.97 & 3.08 & 1.90 \\
\hline
\end{tabular}

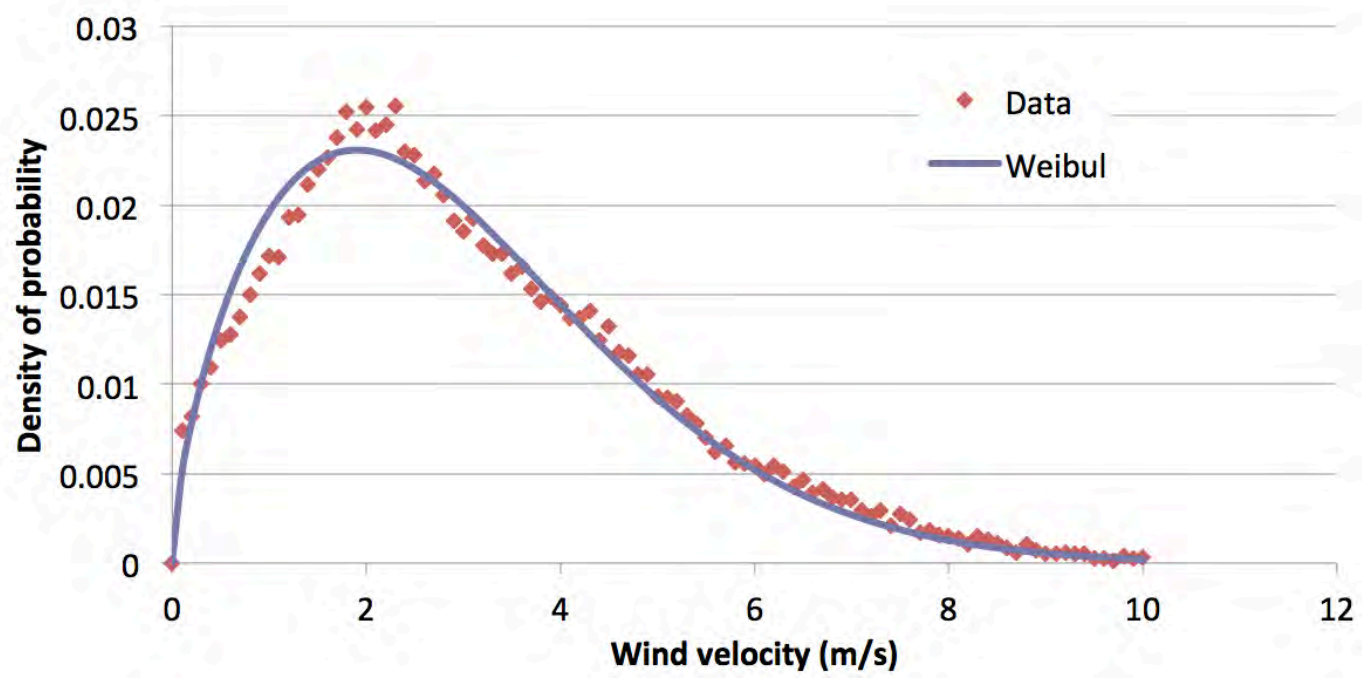

Fig. 2. Comparison between experimental data and the Weibull curve.

The anemometric analysis shows that the mean wind velocity at $20 \mathrm{~m}$ from the ground is equal to $3.08 \mathrm{~m} / \mathrm{s}$. This value is comparable with the aerogenerator cut-in velocity $(2.5 \mathrm{~m} / \mathrm{s})$ and so it demonstrates that the site does not have a good wind potential. Nevertheless it is important to remark that at $35 \mathrm{~m}$ from the ground the mean wind velocity is equal to $4.9 \mathrm{~m} / \mathrm{s}$ as the Wind Atlas of Apulia Region [11] shows. In other words, the mean wind velocity has to be halved going from $20 \mathrm{~m}$ to $35 \mathrm{~m}$ of height from the ground: this issue is common to many sites in urban area and it represents a big problem in order to achieve good performance from micro wind turbines.

Over experimentation time, more parameters have been measured as voltage, current and electric power. These data have been organized and analysed as function of wind direction. In this way it has been possible to study the influence of the shape of the building on the aerogenerator performance.

Fig. 3 shows the measured electric power for wind direction North as a function of wind velocity. Besides it is possible to see the comparison between the mean electric power (best fit of the measures of power - red curve) and the nominal electric power (orange curve). Particularly, for wind velocity up to $3 \mathrm{~m} / \mathrm{s}$ the mean power curve is higher than nominal one, within 3 and $4 \mathrm{~m} / \mathrm{s}$ the two curves are about similar and over $4 \mathrm{~m} / \mathrm{s}$ the mean power curve is lower with respect to the nominal one. Moreover it is possible to observe a noticeable variability of measures due to the irregularity of wind velocity in the site under investigation. 


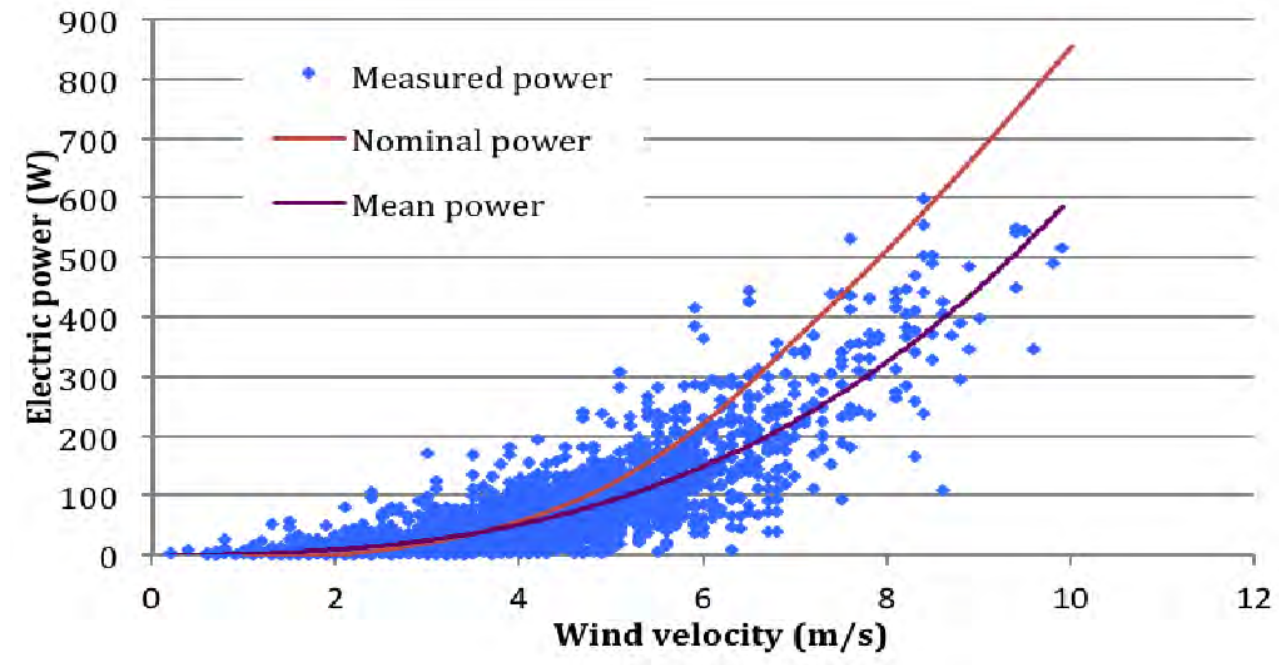

Fig. 3. Electric power output as function of wind velocity (wind direction North). The blue points indicate the measures of power, the red curve indicates the mean power (best fit of the measures) and the orange curve indicates the nominal power.

In order to complete the experimental data analysis, the measured electric power has been examined for each wind direction as Fig. 4 shows.

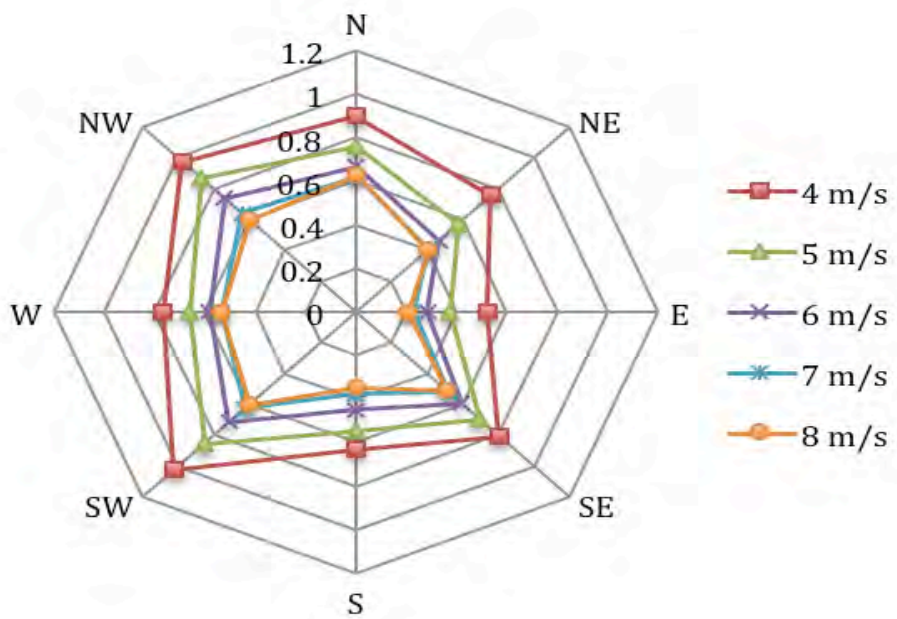

Fig. 4. Ratio between measured electric power and seminal electric power as function of wind direction and intensity

Fig. 4 demonstrates that electric power is very influenced by the wind direction, or in other words, this parameter strictly correlate with the intensity of the wake due to the shape of the building. These effects are more evident by observing the ratio between mean power and nominal power that decreases for high values of wind velocity and for all the considered directions.

\subsection{CFD analysis}

To fully understand the fluid-dynamic phenomena that influence the wind turbine performance several numerical simulations have been carried out by using the software FLUENT. All results are reported next.

The CFD post-processing analysis was developed taking into account for each wind direction four sections of the calculation domain. Particularly, three sections were positioned 
transversely to the wind direction (the first one was placed ten meters forward the building, the second one close to the aerogenerator and the third one ten meter rear the building) and one longitudinal section was placed parallel to the wind direction. This section is very interesting because it shows the flow evolution along the building.

Numerical simulations have been carried out considering the wind velocity within the range $4 \div 8 \mathrm{~m} / \mathrm{s}$ like to experimental analysis. Fig. 5 shows the results along the longitudinal sections for wind directions N-S (North is the prevalent wind direction), in the case of wind velocity equal to $6 \mathrm{~m} / \mathrm{s}$ (mean velocity within the range $4 \div 8 \mathrm{~m} / \mathrm{s}$ ). It is important to notice that in the other cases under investigation (wind velocity equal to $4,5,7$ and $8 \mathrm{~m} / \mathrm{s}$ and other wind directions) the results are qualitatively similar to the case shown next.

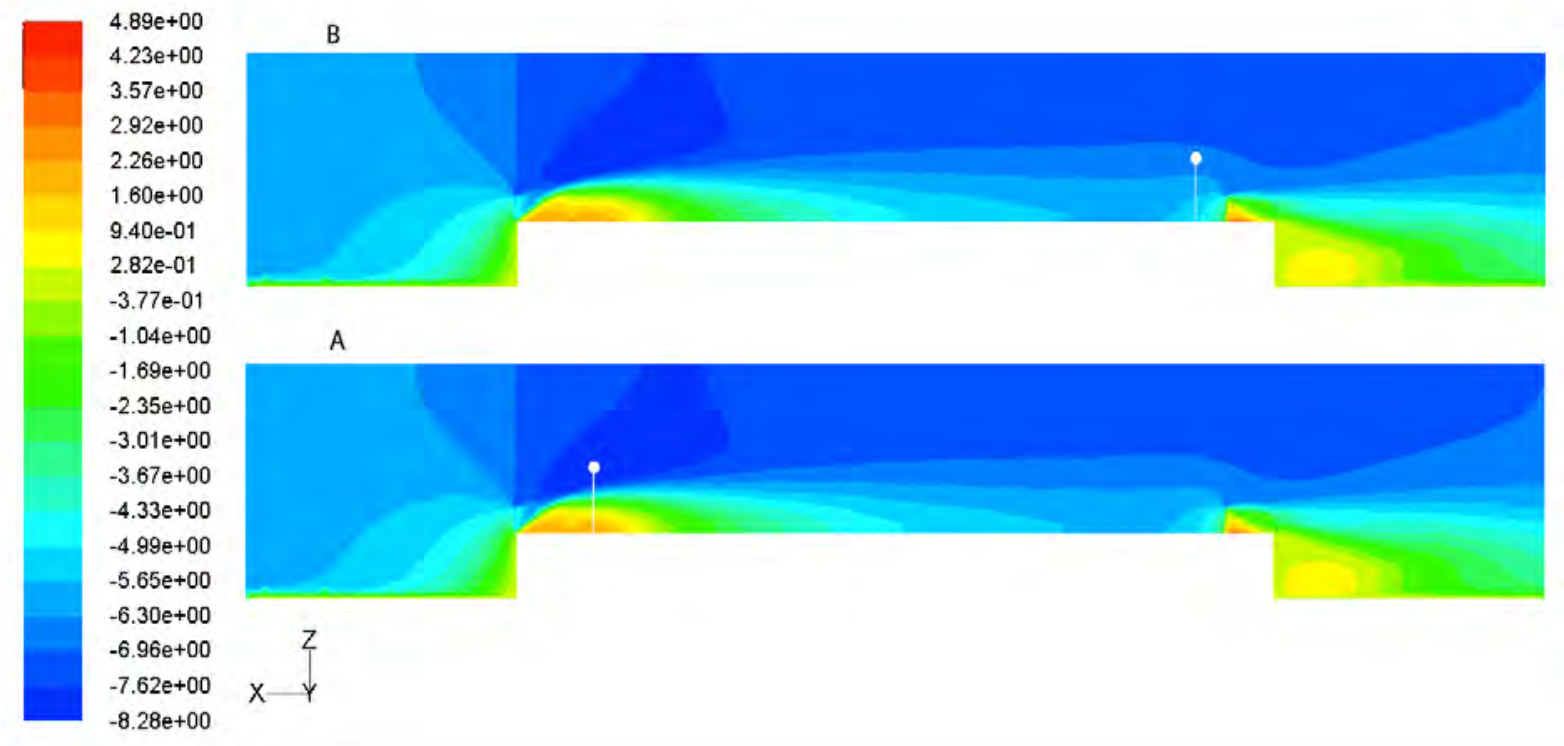

Contours of X Velocity $(\mathrm{m} / \mathrm{s})$

FLUENT 6.2 (3d, dp, segregated, ske)

Fig. 5. Contours of $X$ wind velocity: wind intensity on the boundary: $6 \mathrm{~m} / \mathrm{s}$; wind direction: North (A) and South (B); the pole is sketched by a line and a white circle

As the contours of $\mathrm{X}$ wind velocity demonstrate (Fig. 5), close to the aerogenerator there is a very strong vorticity phenomenon, whereas above this area the wind velocity rise quickly over to $8 \mathrm{~m} / \mathrm{s}$, against an inlet wind velocity equal to $6 \mathrm{~m} / \mathrm{s}$.

These results allow achieving a possible understanding of the experimental results reported in Fig. 3 and Fig. 4: the building generates an increment both of wind velocity and of vorticity influencing the aerogenerator performance; in fact the electric power results meanly lower than the nominal one, due to the strong vorticity, but in some cases the higher values of wind velocity results in a higher electric power output with respect to the nominal one. For example, under meteorological condition with wind velocity equal to $6 \mathrm{~m} / \mathrm{s}$ the maximum measure of electric power matches the nominal power curve for a wind intensity equal to 8 $\mathrm{m} / \mathrm{s}$, as the analysis of Fig. 3 and Fig. 5 reveals.

Changing wind direction from North to South (Fig. 5B), the wind velocity distributions are similar to the previous case (wind direction North - Fig. 5A), with an opposite relative position of the aerogenerator. 
According to experimental results, the longitudinal sections North-South show bigger wind intensity when the direction is North and so also the experimental electric power results bigger than the case South.

Another important consideration can be done taking into account the results shown in Fig. 3 . As it is described before, for wind velocity up to $3 \mathrm{~m} / \mathrm{s}$ the mean power curve is higher than nominal one: in this case the wind intensification effects due to the building are predominant on the vorticity. Instead, when the wind rises over to $4 \mathrm{~m} / \mathrm{s}$ the vorticity generated by the wake of the building becomes prevalent on the wind intensification effects, cutting the aerogenerator performance.

To define the best location for the horizontal axis micro wind turbine has to be take into account the turbulence intensity, defined as the ratio of the magnitude of the root mean square turbulent fluctuations to the reference velocity:

$I=\frac{\sqrt{\frac{2}{3} k_{e}}}{V_{r e f}}$

where $k_{e}$ is the turbulence kinetic energy and $v_{\text {ref }}$ is the mean velocity magnitude for the flow. Fig. 6 shows the comparison between the contours of $\mathrm{X}$ wind velocity and turbulence intensity. This evaluation allows defining the best location for the horizontal axis micro wind turbine in urban area. In fact, by overlapping areas of higher X velocity with areas of lower turbulence intensity it is possible to individuate an area where the aerogenerator can gives maximum performance.

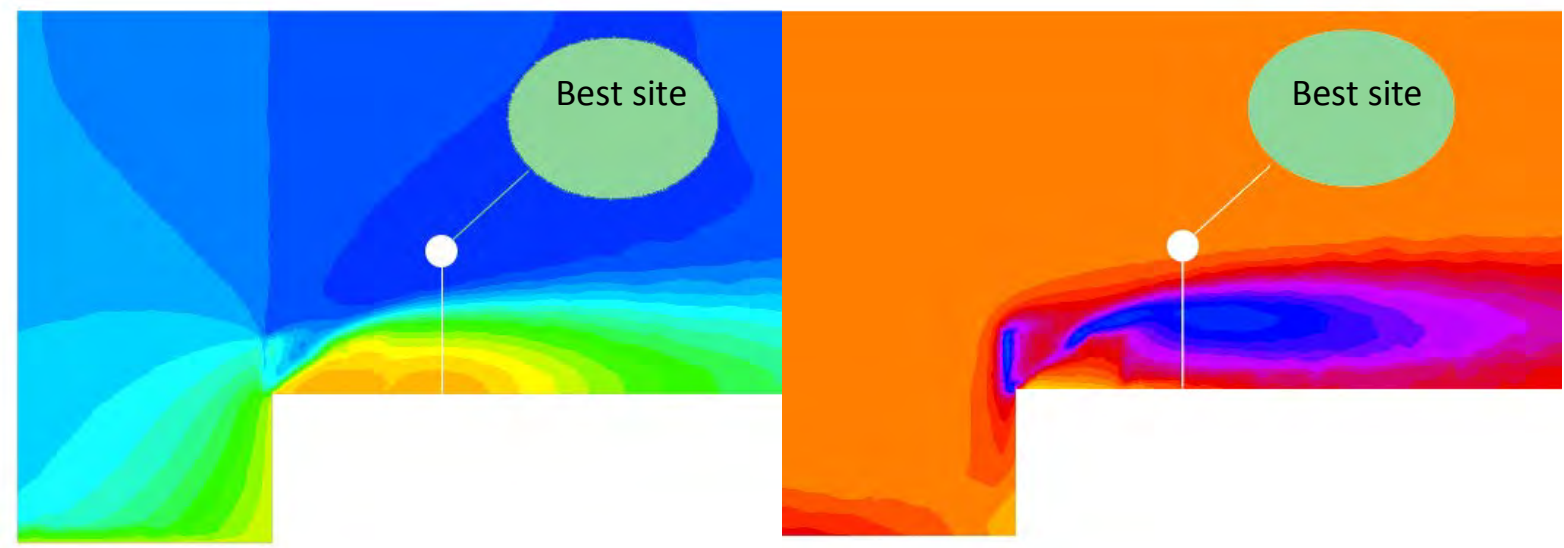

Fig. 6. Comparison between contours of $X$ wind velocity and turbulence intensity. The pole is sketched by a line and a white circle. The best site in sketched by a green ellipse

\section{Conclusions}

This work focuses on experimental and numerical analysis about the electric power generation from a $1 \mathrm{~kW}$ horizontal-axis aerogenerator installed on the roof of the Engineering building at the University of Salento in urban area. Particularly the influence of the building on the micro wind turbine performance has been studied.

Experimental data were collected over a period of time of three years during which it $\mathrm{w}$ as observed a perpetual transient condition of the microturbine that reduces its performance. Then to fully understand this occurrence and in order to value the performance of the 
horizontal axis wind turbine, several CFD calculations have been carried out, taking into account different meteorological conditions. Numerical simulations calculated wind velocity fields and turbulence intensity above the building due to fluid-dynamic effects.

The experimental and numerical results of this study reveal that the siting of the horizontalaxis micro wind turbine on a building should allow to exploit bigger wind intensity, but often this advantage is neglected from turbulence phenomena; in fact, in the case under investigation, the measured aerogenerator efficiency appears lesser in comparison with the nominal performance curve. But, the best site can be found by crossing the contours of wind velocity with the turbulence intensity fields. In this way it is possible to localize an area (best location) where the aerogenerator can gives maximum performance.

In conclusion, the result presented in the present investigation showed that horizontal axis wind turbines suffer from wake effect due to buildings, therefore best sites in urban area have to be identified by a careful fluid dynamic analysis aimed at evaluating all causes that can reduce significantly the performance of the generator.

\section{References}

[1] T. Devezas, D. LePoire, J.C.O. Matias and A.M.P Silva, Energy scenarios: Toward a new energy paradigm, Futures, 40(1), 2008, pp. 1-16.

[2] H. Schiffer, WEC energy policy scenarios to 2050, Energy Policy, 36(7), 2008, pp. 24642470 .

[3] V.D.Z. Bob and G. Reyen, Climate sensitivity uncertainty and the necessity to transform global energy supply, Energy, 2006, pp. 2571-2587.

[4] G.J. Dalton, D.A. Lockington, T.E. Baldock, Feasibility analysis of stand-alone renewable energy supply options for a large hotel, Renewable Energy, 33(7), 2008, pp. 1475-1490.

[5] R. Sauter, J. Watson, Strategies for the deployment of micro-generation: implications for social acceptance, Energy Policy, 35(5), 2007, pp. 2770-2779.

[6] S.R. Allen, G.P. Hammond, M.C. McManus, Prospects for and barriers to domestic micro-generation: a United Kingdom perspective, Applied Energy, 85(6), 2008, pp. 528544.

[7] J. Kelleher, J.V. Ringwood, A computational tool for evaluating the economics of solar and wind microgeneration of electricity, Energy, 34, 2009, pp. 401-409.

[8] J. Watson, Co-provision in sustainable energy systems: the case of micro-generation, Energy Policy, 32(17), 2004, pp. 1981-1990.

[9] J. He, C.C.S. Song, Evaluation of pedestrian winds in urban area by numerical approach, Journal of Wind Engineering and Industrial Aerodynamics, 81, 1999, pp. 295-309.

[10] G.T. Johnson, L.J. Hunter, Urban wind flows: wind tunnel and numerical simulations - a preliminary comparison, Environmental Modelling \& Software, 13, 1998, pp. 279-286.

[11]L. Tornese, A. de Risi, D. Laforgia, Atlante eolico della Regione Puglia, 2008, Graficazerottanta. 